JOURNAL OF SECURITY AND SUSTAINABILITY ISSUES

ISSN 2029-7017/ISSN 2029-7025 (online)

2020 Volume 9 January

http://doi.org/10.9770/jssi.2020.9.J(3)

\title{
Scopus
}

\section{IMPACT OF SELECTED FACTORS ON JOB PERFORMANCE OF EMPLOYEES IN IT SECTOR: A CASE STUDY OF INDONESIA}

\author{
Chutikarn Sriviboon \\ Suan Sunandha Rajabhat University, Bangkok, Thailand \\ E-mail: chutikarn.sr@ssru.ac.th
}

Received 22 March 2019; accepted 10 December; published 30 January 2020

\begin{abstract}
The main objective of the current study is to examine the impact of the corporate entrepreneurship, knowledge management on the job performance of employees of IT sector firms in Indonesia. Additionally, the study has also examined the mediating role of organizational commitment, in the relationship between corporate entrepreneurship, and job performance, and between the knowledge management and the job performance. The firms from the IT (information technology) industry are chosen as a sample of the study. The data is collected with the aid of a questionnaire that is adopted from the prior studies. The study has used the structural equation modeling for the analysis of the data. At earlier stages it is suggested to apply PLS modelling that is at theoretical development stage which let the researcher to confirm and examine the experimental models determining the direct relationship between compete entrepreneurship, knowledge management, organizational commitment, and the job performance are significant at p-value less than 0.05 . The findings of the study highlighted that the compete entrepreneurship, knowledge management, are significant determinants of the organizational commitment. Meanwhile, the study has confirmed that the organizational commitment, mediate in the relationship between corporate entrepreneurship, and job performance, and between the knowledge management and the job performance. The study is among the pioneer study and will be helpful for the policymakers and researchers.
\end{abstract}

Keywords: knowledge management; corporate entrepreneurship; organizational commitment; job performance; IT

Reference to this paper should be made as follows: Sriviboon, C. 2020. Impact of selected factors on job performance of employees in IT sector: a case study of Indonesia. Journal of Security and Sustainability Issues, 9(January), 28-41. http://doi.org/10.9770/jssi.2020.9.J(3)

JEL Classifications: O31

\section{Background}

For most of the researchers, job performance has always been a great challenge (Anesukanjanakul, Banpot, \& Jermsittiparsert, 2019). Job performance has been analyzed by researchers for a number of years in the field of occupational health, management, and industrial psychology of organizations (Zainal et al., 2018; Borisov et al., 2018; Bogdanović et al., 2018; Al-Kahtani, 2018; Jermsittiparsert, Suan, \& Kaliappen, 2019; Bernardi, 2019).

The concept of job performance can be defined as the performance of an employee for a specific tasks or activity (Kwahk \& Park, 2016). This can be considered as behaviors than outcomes. For employers and employees, performance is very importance because it influences the decisions regarding merit, promotions, terminations, and bonuses(Becton et al., 2017). Several scholars have studied job performance among individuals with respect to organizations. The initial study was conducted by Rimer (1993). The researcher argued that productivity of employees could be regulated by identification and regulation of the schedule. The study was based on mechanization and not human aspect within the organization, which lead to criticism (Argyris, 2017). 


\section{JOURNAL OF SECURITY AND SUSTAINABILITY ISSUES}

ISSN 2029-7017/ISSN 2029-7025 (online)

2020 Volume 9 January

http://doi.org/10.9770/jssi.2020.9.J(3)

The perspective of outcome means the result of the behavior of an individual. Outcomes can be resulted by behaviors including sales, assembled engines, number of successful operations, etc. The variables other than the behavior of an individual result in the performance's outcome perspective. The reading lesson perfectly delivered by a teacher is the performance's behavioral perspective. However, one or two students show no improvements in their skills because of lack of intellectual abilities are referred as performance's outcome perspective(Ericsson, 2015). The behavioral aspect of job performance has been adopted consistent with the study of Dainty, (Kwofie et al., 2018). This aspect considers the behavior aspects, which are softer to achieve the success of project. The behaviors of contextual performance and task performance are included in the behavioral aspect of performance(Unterhitzenberger \& Bryde, 2019). In order to achieve competitive edge, most of the organizations required individuals with high performance for achieving the set goals and delivering products/services.

The employees get motivation by high performance and task accomplishment. When an individual is not able to achieve the target, this results in dissatisfaction (Lohmann et al., 2017). The psychological research of an organization and work are linked with the high relevance regarding the performance of an individual (Judge \& Zapata, 2015). Therefore, a literature review was conducted by the researchers. Twelve studies from journals of organizational psychology were studied based on different level of groups, organizational circumstances, and individuals. It was found through literature that almost 146 meta-analyses have been conducted over the last 20 years. Half of these researchers $(54.8 \%)$ were based on the use of individual performance as the main construct. However, most of the researchers $(72.5 \%)$ incorporated performance of individuals as an outcome measure or endogenous variable. Therefore, individual performance was taken as endogenous variable by most of the studies. It was found by six percent meta-researches that individual performance is a predictor or independent variable (Singh, 2018).

The management of knowledge is required time to time. It is not one-time event. It is a continuous process, which requires maintenance. Knowledge management is not once-a-time event. Without improvement or maintenance, it can become out of date. (Drucker, 1992) introduced the knowledge management concept with the idea of knowledge workers. People, who are able to use the knowledge of an organization for developing products, which are intangible, are referred as knowledge workers. Techniques of knowledge management are applied by several organizations in an informal manner, which is not purposely. The awareness about the existence of process of knowledge management is referred as something new in knowledge management. For knowledge management as an asset, every organization should develop a number of skills and instruments in knowledge management (Maier \& Hadrich, 2011).

\section{Hypothesis Development}

\subsection{Job Performance and Knowledge Management}

Benefits of $\mathrm{KM}$ are perceived by public and private organizations by improving efficiency, quality, effectiveness, reduction of operational cost and management learning(Masa'deh et al.,2017). The KM responses from IT sector have significant value, which shows that it can result in overall efficiency. Moreover, IT sector has great contributions in economic development. It was found by the survey study conducted by (Biscotti et al.,2018) that the implementation of KM is based on the knowledge and workforce of an organization. It was found by the study that shifting the behavior of employees for knowledge dissemination is highly complicated issue for knowledge management in the organization.

A relation has been established by previous research studies between performance and knowledge management. It was found by Butt et al. (2019) that the performance of firm can be improved through an effective KM system. 


\section{JOURNAL OF SECURITY AND SUSTAINABILITY ISSUES}

ISSN 2029-7017/ISSN 2029-7025 (online)

2020 Volume 9 January

http://doi.org/10.9770/jssi.2020.9.J(3)

However, it was indicated by Masa'deh et al.(2017) that there is a good relation between knowledge and innovativeness, which improves performance. It was examined by (Maier \& Hadrich, 2011) that implementation of KM can benefit small firms for achieving sustainable competitiveness. It was found by Butt et al. (2019) that KM of great significance for telecommunication and biotechnology industries to achieve sustainable competitive advantage. It was argued by Masa'deh et al. (2017) that KM is a dynamic capacity is associated with performance of firms in manufacturing sector of Taiwan. It was indicated by Judge and Zapata (2015) that there is a positive and significant relation between capabilities of KM and performance of Thai electronic firms.

A positive association was found by Jain and Moreno (2015) between financial performance and practices of knowledge management. However, some researchers found a significant and positive relation between performance and knowledge management(Kwofie et al.,2018). The performance and Knowledge management among SMEs was analyzed by(Ha et al.,2016). It was found that knowledge management has an influence on marketing performance in the auto sector. It was revealed by the study of (Soto-Acosta et al.,2016) on manufacturing sector that there is a positive and significant relation between organizational performance and knowledge management. Ha et al. (2016) and Soto-Acosta et al. (2016) conducted similar studies in the context of Malaysia. It was found that a positive and significant influence is carried out by knowledge management on SME's performance. The IT sector organizations were also analyzed by several studies. For instance, it was found by Mao et al. (2016) that knowledge management can be improved by IT sector organization in communication stream. However, this is not done in measurement and facilitation. A model was successfully developed by Kamruddin and Akram (2016) based on the previous theoretical studies using KM in IT sector firms. The importance of KM modeling was shown by the researchers in initiative based on of science in the public service of Canada. Five elements were included in the model such as culture, leadership, technology, process, and measurement. It was concluded that leaders can overcome several organizational challenges through KM. Leaders can understand and use the KM enablers, which is a significant outcome of investment in knowledge. Similarly, it was suggested by Alkhuraiji et al. (2016) that a crucial role can be played by KM in decision-making and delivery of public service. It was proved by Kamruddin and Akram (2016) that performance is associated with knowledge sharing. Moreover, different dimensions of knowledge sharing influence the performance in distinct manner. However, it was revealed by Alkhuraiji et al.(2016) that several researchers have admitted that different concepts support the relation of performance and knowledge sharing. The empirical researchers on these associations are limited. It was discovered by Brahma and Mishra (2015) in their study that the changing behavior of workers is the KM issue of IT sector, which is highly complicated.

The maintenance of data is another issue along with the buildup requirement. Further issues include gathering of knowledge, provision of structured training for employees and developing a norm, which is value sharing to improve sharing of knowledge (Koriat \& Gelbard, 2018). It was suggested by the researchers that the focus of IT sector organizations should be on managing knowledge for responding to the requirements of customer, improved quality of service and decision-making.

A study was conducted by Massaro et al. (2015) on implementation of KM accounting organizations of IT sector. It was revealed by the findings that a positive association exists between the process of knowledge sharing and KM with performance. The relation between organizational performance, skills, and knowhow of ICT was significantly negative. It was due to the reason the accountants considered themselves expert and professional. However, they had limited exposure to ICT while job performance (Noor et al., 2016). The Office of Accountant General called for a well-planned and clear KM policy to be implemented. Commitment and support are also provided by top management for successful implementation of KM programs in accounting sector. It was found by another research conducted by Mao et al.(2016) on the employees in IT sector. The study found that competitive advantage can be gained through KM. biasness emerged in self-serving between employees for their readiness of knowledge sharing as compared with the willingness of co-workers to share knowledge. The basic issues were identified as low level 


\section{JOURNAL OF SECURITY AND SUSTAINABILITY ISSUES}

ISSN 2029-7017/ISSN 2029-7025 (online)

2020 Volume 9 January

http://doi.org/10.9770/jssi.2020.9.J(3)

of communication, shortage of time and interpersonal skills. Moreover, low IT systems were a barrier for the organization. Studies conducted by were also based on KM in Malaysian organization (Malarvizhi et al., 2016) and (Massaro et al.,2015). However, no study has been conducted on job performance and KM with reference to Malaysian local government. In this regard, the following research hypothesis has been developed:

H1: knowledge management (KM) has significant impact on the job performance.

\subsection{Corporate Entrepreneurship and Job Performance}

Corporate Entrepreneurship (CE) is a clear concept. However, it has been suggested by previous studies that it can occur in different forms. This is referred as activities such as opportunistic, imitative, administration, and incubate (Hoque et al.,2017). CE can occur individually/ collectively, creation of autonomous business and initiative from below. In this study, the individual behavior of CE has been adopted, which directors towards entrepreneurship orientation. The association between performance and CE (corporate entrepreneurship) has been focused in literature. It has been argued by most of the researchers that the overall performance of a firm can be improved through CE. CE can be a measure for generative good financial outcomes along with market or product diversification(An et al.,2018). CE was considered by Hoque et al. (2017) as an interpreter for small firms' growth. However, CE was regard by (Ha et al., 2016) as a source of competitive advantage. The success of an organization is based on CE. The performance of a company can be improved through CE creation of new knowledge and improving the existing knowledge (Ferraris et al.,2017). Moreover, it enhances the innovation of product/service/processes for local and international business.

The relation between venture of CE and innovativeness was analyzed by Chen et al. (2015) using a sample of 231 medium size companies in US. The results of the study revealed that a positive and significant influence is created by innovativeness on growth, profitability, and wealth of shareholders. However, the relation between performance and CE as examined by Malarvizhi et al. (2016) using a sample of 141 companies in Slovenia and 51 firms in US. The researcher applied SEM approach. It was found that there is a significant relation between CE and growth of firms in US. However, there was no relation between profitability and CE. Further, it was found by (Massaro, Dumay, \& Garlatti, 2015)that performance (new wealth, profitability, and growth) is significantly related with CE. It was found by Popadic et al. (2016) that slight difference exists in alliance item and CE between Romania and Slovenia. Later, it was suggested that innovation in product develop is crucial for economic growth and performance of firms. The Chinese firms were studied by Bedoya. (2018) and it was found that the three CE's dimensions including proactive, risk-taking, and innovation have positive association with CE. Chen et al. (2015) developed three dimensions, which were used by Butt et al. (2019) including risk taking, innovativeness, and proactiveness. The research was conducted between corporate entrepreneurship, knowledge-based resources and SME's performance. It was indicated by results that performance of firm is linked with knowledge-based resources, which strengthens the association with CE.

A relation was found by Story et al.(2015) between performance and innovativeness. However, it was revealed by Popadic et al. (2016) that there is a related between dimensions of innovativeness, proactiveness, and performance are linked with each other. The relation between performance and CE was examined by An et al.(2018) between 172 SMEs in the manufacturing sector of Sweden. The study found no association between CE's proactiveness component and growth of performance and sales. It was discovered by Masa'deh et al. (2017) that the relation between gender and radical is moderated by innovativeness. However, the same variables are moderated negative by risk taking. CE was linked with measurements (financial and non-financial) in terms of performance by Unterhitzenberger and Bryde (2019). The performance's financial measurement is categorized as market share, growth, and profitability. However, affective commitment and job satisfaction among members of organizations were suggested by non-financial measurements. Financial measurement is of great importance, but non-financial 


\section{JOURNAL OF SECURITY AND SUSTAINABILITY ISSUES}

ISSN 2029-7017/ISSN 2029-7025 (online)

2020 Volume 9 January

http://doi.org/10.9770/jssi.2020.9.J(3)

measurement can be employed in relation with the outcomes of entrepreneurship. The need to develop spirit of entrepreneurship was investigated between workforce of Malaysia by Ericsson (2015). It was found that work discretion, management support, reinforcement, resource, and availability of time create significant influence on intrapreneurship. It was also found that intrapreneurship is positively linked with job performance. Further, it was suggested that intrapreneurship should be promoted in the manufacturing sector.

H2: Corporate Entrepreneurship (CE) has significant impact on the job performance.

\subsection{Mediating role of Organizational Commitment}

Organizational commitment has been linked with employee work by previous research studies. For instance, it was found by Ahmed (2016) that there exists a positive association between performance of employee and organizational commitment. However, a significant strength of predictor is not presented by commitment. It was confirmed by Bedoya et al. (2018) that there is a significant and positive influence created on performance of employees by organizational commitment. It was also found by Umrani et al. (2018) in their study on Taiwan that a construction outcome is created by organizational commitment on job performance. It was found by Massaro et al.(2015) that a significant relation exists for affective commitment with job performance. However, these are not continuance or normative commitments. In the similar way, it was found by Hoque et al. (2017) that affective commitment has been found to be linked significantly with job performance out of all three organizational commitment's dimensions.

The indirect relation was found by Story et al. (2015) in which a complete mediating role was played by organizational commitment in defining the influence of transformational leadership on performance of employees. It has been found by several studies that a mediating role is played by organizational commitment in the relation of performance on job with other factors such as style of leadership, work commitment, security of job, leadership behavior, exchange of member-leader, relation of performance and stress, and job satisfaction, goal orientation, and justice-benevolence distribute. Alternatively, it was found by Ahmed (2016) in the research on public administrators of Malaysia that the relation between performance and work climate is not fully mediated by organizational commitment. Several studies have analyzed the role of organizational commitment in mediating the relation between endogenous and exogenous variables. It was proposed by Bedoya et al. (2018) that mediating role of organizational commitment has been incorporated in their conceptual paper. Evidence was found by researchers that organizational commitment and employee involvement are the cultural variables, which create influence on practices of human resource management. However, performance and productivity are influenced as well. The relation between job commitment, job satisfaction, job fit of individuals, and intention to quit was analyzed by Umrani et al. (2018) in different Pakistani organizations. It was found that the relation between intention to quit job and job fit of individual was moderated by organizational commitment. However, these studies have not focused on the influence of organizational commitment as a moderator on the associations in IT sector. There is need for an additional study to examine the role of organizational commitment as a moderator with reference to the job performance of employees in IT sector organizations. Therefore, the following research hypothesis has been developed:

H3: Corporate entrepreneurship (CE) has significant impact on the organizational commitment OC).

H4: Knowledge management (KM) has significant impact on the organizational commitment (OC).

H5: Organizational commitment (OC) mediates the relationship between Corporate entrepreneurship (CE) and the job performance (JP).

H6: Organizational commitment (OC) mediates the relationship between Knowledge management (KM) and the job performance (JP). 


\section{JOURNAL OF SECURITY AND SUSTAINABILITY ISSUES}

ISSN 2029-7017/ISSN 2029-7025 (online)

2020 Volume 9 January

http://doi.org/10.9770/jssi.2020.9.J(3)

\section{Methodology}

The aim of this study is analysis of association between latent variables so, for this we have chosen the method of latent analysis to investigate the relation. For data analysis there is another option of covariance-based SEM technique for researcher but for this method data must be normally distributed (Hair et al., 2011). In the current study we have used Partial Least Square Structural Equation Modelling (PLS-SEM) which does not have limitation for normal distribution of data. (Hair et al., 2011) has suggested that partial least square (PLS) technique is the powerful and well-known alternate to SEM like AMOS and LISREL.

Though in case of complex model this technique is more suitable such as the models which have hierarchical constructs of mediation and moderation effects and have comprehensive disaggregation methods (Preacher et al., 2010). At earlier stages it is suggested to apply PLS modelling that is at theoretical development stage which let the researcher to confirm and examine the experimental models.

Moreover, the best part about the PLS technique is it more suitable for analyzing the prediction-oriented research in which methodology help researcher to describe the endogenous constructs. So, for analysis before choosing any statistical method we have tested following assumptions.

Generally, in research specifically in social research for data analysis there are three key steps. 1) cleaning and organizing the data, 2) description of data, 3) Estimation and testing of hypothesis which is also known as inferential statistics. Furthermore, the stage of data peroration contains the accuracy of data and its checking. In contrast for the description of key features of data we use descriptive statistics thus it also allows to give explanation about all involved variables and sample of the study. Two analysis techniques were used to define nature of variables and their relationship in this study 1) Inferential analysis, 2) descriptive analysis. We have used Partial Least Squares Structural Equation Modelling (PLS-SEM) to define data and relation between the variables. The response rate of the current study is 63.5 percent, which is considerably higher than the minimum level of 30 percent.

\section{Results}

For the determination of measurement or outer model we have used partial least square structural equation modelling (PLS-SEM). We have taken the following steps to check the goodness of fit in the model. At first, we have established the validity of construct which includes factor loadings, composite reliability (CR) Cronbach alpha and convergent validity. In second step through the (Fornell \& Larcker, 1981) criterion we have evaluated the discriminant validity. We have the measurement model in figure 2. 


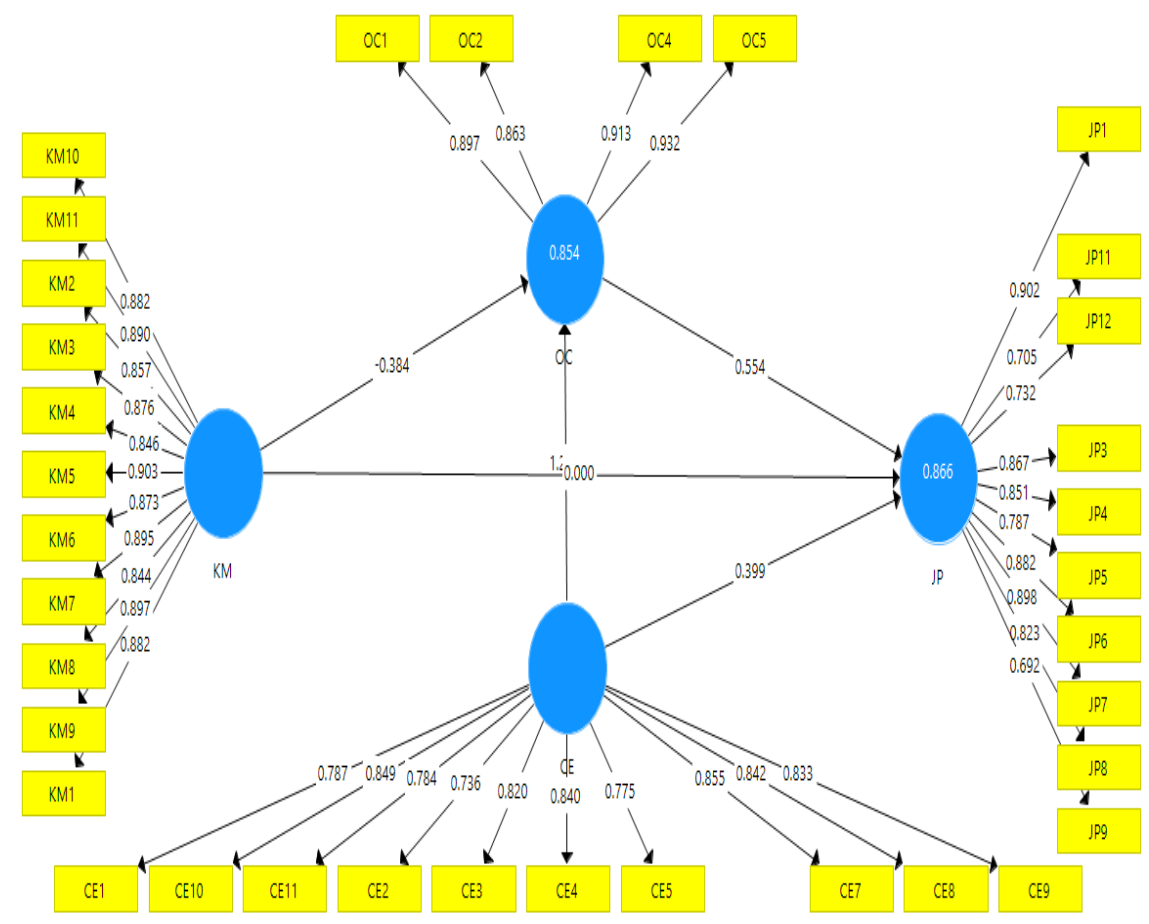

Figure 1. Measurement Model

The items namely, JP2, JP10, CE6, and OC3 with loadings less than 0.70 are deleted form the analysis.

Table 2. Outer loadings

\begin{tabular}{|c|c|c|c|c|}
\hline & CE & JP & KM & OC \\
\hline CE1 & 0.787 & & & \\
\hline CE10 & 0.849 & & & \\
\hline CE11 & 0.784 & & & \\
\hline CE2 & 0.736 & & & \\
\hline CE3 & 0.820 & & & \\
\hline CE4 & 0.840 & & & \\
\hline CE5 & 0.775 & & & \\
\hline CE7 & 0.855 & & & \\
\hline CE8 & 0.842 & & & \\
\hline CE9 & 0.833 & & & \\
\hline JP1 & & 0.902 & & \\
\hline JP11 & & 0.705 & & \\
\hline JP12 & & 0.732 & & \\
\hline JP3 & & 0.867 & & \\
\hline
\end{tabular}




\begin{tabular}{|c|c|c|c|c|}
\hline JP4 & & 0.851 & & \\
\hline JP5 & & 0.787 & & \\
\hline JP6 & & 0.882 & & \\
\hline JP7 & & 0.898 & & \\
\hline JP8 & & 0.823 & & \\
\hline JP9 & & 0.700 & & \\
\hline KM10 & & & 0.899 & \\
\hline KM11 & & & 0.857 & \\
\hline KM2 & & & 0.876 & \\
\hline KM3 & & & 0.846 & \\
\hline KM4 & & & 0.903 & \\
\hline KM5 & & & 0.873 & \\
\hline KM6 & & & 0.895 & \\
\hline KM7 & & & 0.844 & \\
\hline KM8 & & & & 0.897 \\
\hline KM9 & & & & 0.897 \\
\hline OC1 & & & & 0.983 \\
\hline OC2 & & & & \\
\hline OC4 & & & & \\
\hline OC5 & & & & \\
\hline KM1 & & & & \\
\hline
\end{tabular}

In data analysis process degree of measures consistency is explained by the reliability of construct. By controlling the other variables, we can choose for the measurement of reliability. So, assume that reliability of measure is achieved if the questionnaires of respondents are consistent with individual items of measure. According to the study of Hair et al.(2011) the degree to which we can measure a concept with the help of generated items set they were supposed to measure is called the construct validity.

Table 2. Reliability

\begin{tabular}{|l|l|l|l|c|}
\hline & Cronbach's Alpha & rho_A & CR & (AVE) \\
\hline CE & 0.943 & 0.947 & 0.951 & 0.661 \\
\hline JP & 0.944 & 0.952 & 0.952 & 0.668 \\
\hline KM & 0.970 & 0.971 & 0.973 & 0.769 \\
\hline OC & 0.923 & 0.924 & 0.945 & 0.813 \\
\hline
\end{tabular}

(Fornell \& Larcker, 1981) and (Hair, Ringle, \& Sarstedt, 2011), has suggested the that the value of CR must exceeds the value of 0.70 as shown in Table 2. Furthermore, results also shows that values of Average variance extracted (AVE) were higher than the suggested range. Which shows that the validity of construct is acceptable. Results have also confirmed the convergent validity of outer model. We have also used the Fornell \& Larcker (1981) criterion for the confirmation of discriminant validity. For all the constructs the square root of AVE was diagonally placed in correlation matrix shown in Table 2. So, in short if outer models construct validity is recognized then the results of hypothesis testing will be considered as valid and reliable. 
JOURNAL OF SECURITY AND SUSTAINABILITY ISSUES

ISSN 2029-7017/ISSN 2029-7025 (online)

2020 Volume 9 January

http://doi.org/10.9770/jssi.2020.9.J(3)

Table 3. Discriminant validity

\begin{tabular}{|l|l|l|l|l|}
\hline & $\mathbf{C E}$ & JP & KM & OC \\
\hline $\mathbf{C E}$ & 0.813 & & & \\
\hline $\mathbf{J P}$ & 0.800 & 0.897 & & \\
\hline $\mathbf{K M}$ & 0.868 & 0.729 & 0.877 & \\
\hline $\mathbf{O C}$ & 0.804 & 0.815 & 0.691 & 0.901 \\
\hline
\end{tabular}

The measurement of structural model is the next step in PLS-SEM, the structural model is shown in the figure 3 below

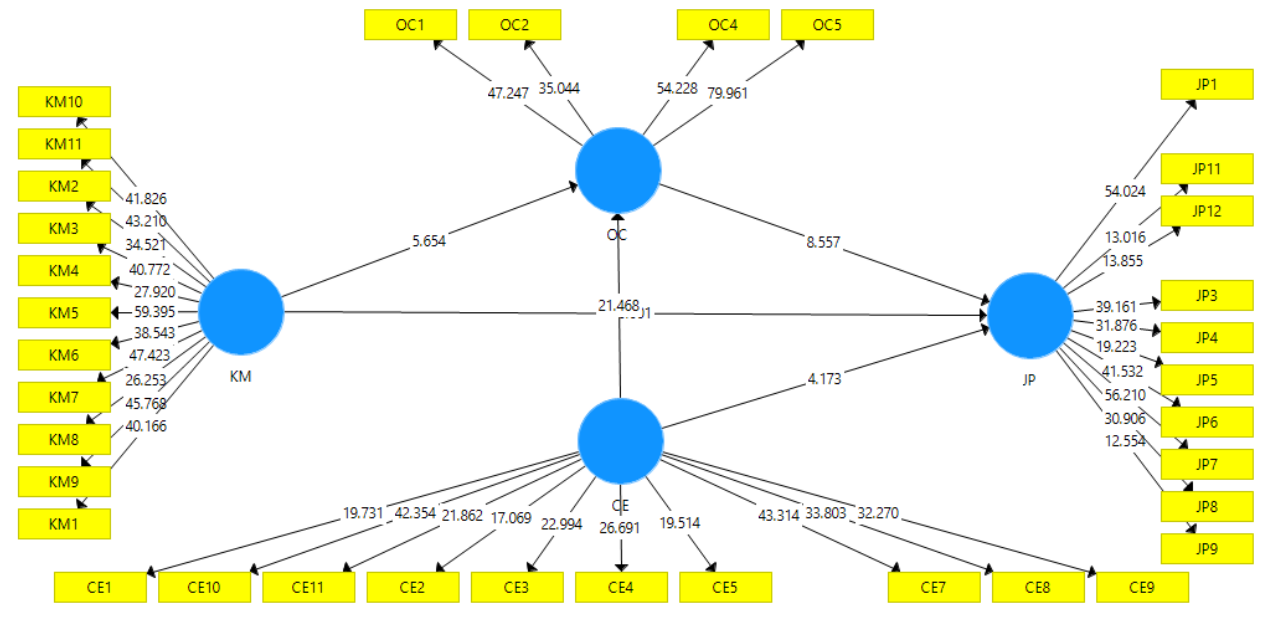

Figure 3. Structural Model

We have explained the direct relation between the variables of the study in the table 4 below all the hypothesis are accepted significantly. All the path CE -> JP, CE -> OC, KM $\rightarrow$ JP, KM -> OC, and OC -> JP determining the direct relationship between compete entrepreneurship, knowledge management, organizational commitment, and the job performance are significant at p-value less than 0.05. The findings of the study highlighted that the $\mathrm{CE}$, and $\mathrm{KM}$, are significant determinants of the OC. Meanwhile, CE and KM have significant impact on the JP.

Table 4. Direct relationship

\begin{tabular}{|l|l|l|l|l|c|}
\hline & $(\mathbf{O})$ & $(\mathbf{M})$ & $(\mathbf{S T D E V})$ & $(|\mathbf{O} / \mathbf{S T D E V}|)$ & $\begin{array}{c}\mathbf{P} \\
\text { Values }\end{array}$ \\
\hline $\mathbf{C E}->\mathbf{J P}$ & 1.084 & 1.072 & 0.070 & 15.598 & $\mathbf{0 . 0 0 0}$ \\
\hline $\mathbf{C E}->\mathbf{O C}$ & 1.238 & 1.226 & 0.058 & 21.468 & $\mathbf{0 . 0 0 0}$ \\
\hline KM $>$ > JP & -0.213 & -0.198 & 0.085 & 2.511 & $\mathbf{0 . 0 0 6}$ \\
\hline KM $>$ OC & -0.384 & -0.370 & 0.068 & 5.654 & $\mathbf{0 . 0 0 0}$ \\
\hline OC $>$ JP & 0.554 & 0.550 & 0.065 & 8.557 & $\mathbf{0 . 0 0 0}$ \\
\hline
\end{tabular}


The study has also examined the mediating role of organizational commitment in the relationship between the corporate entrepreneurship, knowledge management, and the job performance. The findings of the study have revealed the fact that the paths $\mathrm{CE} \rightarrow \mathrm{OC} \rightarrow \mathrm{JP}$, and $\mathrm{KM} \rightarrow \mathrm{OC} \rightarrow \mathrm{JP}$ are significant.

Table 5. Mediation

\begin{tabular}{|l|c|c|c|c|c|}
\hline & $(\mathbf{O})$ & $(\mathbf{M})$ & $(\mathbf{S T D E V})$ & $(\mid \mathbf{O} / \mathbf{S T D E V})$ & P Values \\
\hline $\mathbf{C E}$-> OC $\boldsymbol{~ > ~ J P ~}$ & 0.686 & 0.675 & 0.090 & 7.614 & $\mathbf{0 . 0 0 0}$ \\
\hline $\mathbf{K M}$-> OC $>$ > JP & -0.213 & -0.204 & 0.048 & 4.448 & $\mathbf{0 . 0 0 0}$ \\
\hline
\end{tabular}

The reflective accuracy of the model is represented by the coefficient of determination which is assessed by taking the square of correlation between the actual and predicted endogenous constructs. According to the study of (Hair et al.(2014) the coefficient illustrates the combine effect of on endogenous latent construct by the exogenous construct of model. The range of $\mathrm{R}$ square lies between 0 to 1 . Which means as much the value of $\mathrm{r}$ is greater shows the higher level of predictive accuracy. Though no rule of thumb is recommended for the value of $\mathrm{R}$ square but According to (Hair et al.(2014) if the value of $R$ square is 0.25 it shows weak forecasting if the value of $R$ square is 0.50 it's the moderate level of prediction whereas if the value of $R$ square is 0.75 then it is substantial.

Table 6. R-square

\begin{tabular}{|l|l|}
\hline & R Square \\
\hline JP & 0.866 \\
\hline OC & 0.854 \\
\hline
\end{tabular}

The blindfolding procedure is emlpoyed for the determination of the predictiev abiluty of the concptua mdoel. The blindfolding resulst are mappe din the figure 4.

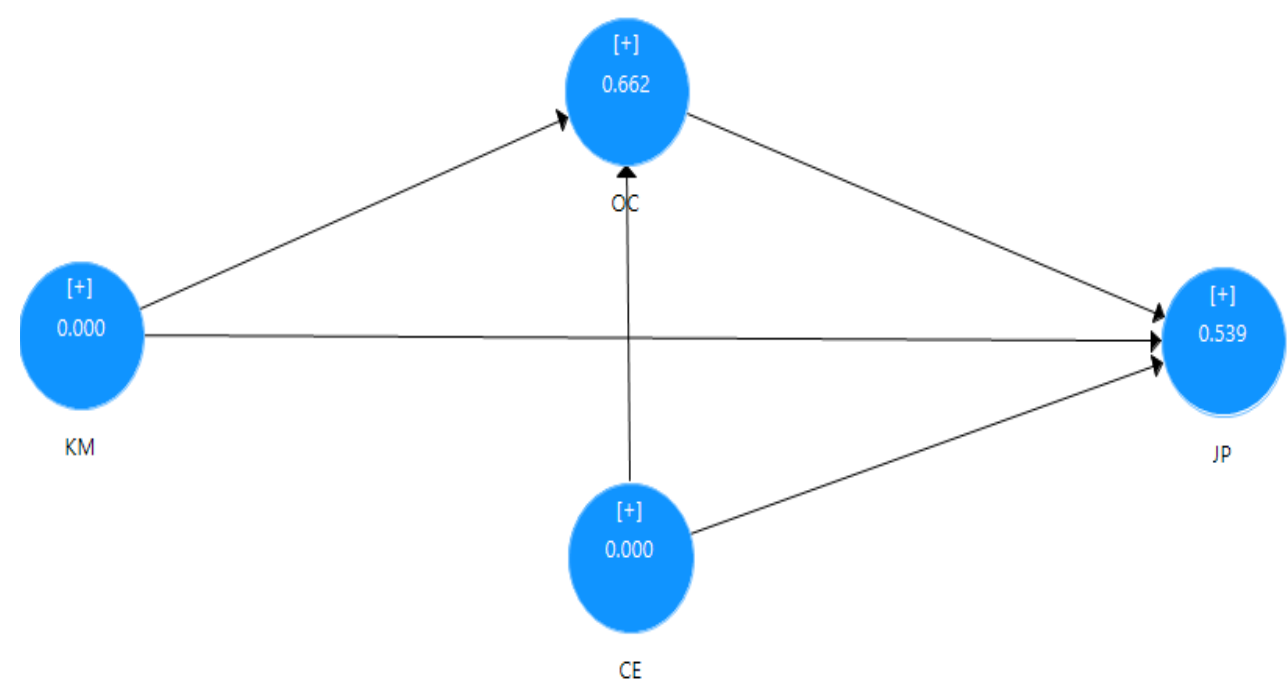

Figure 4. Blind folding 


\section{JOURNAL OF SECURITY AND SUSTAINABILITY ISSUES}

ISSN 2029-7017/ISSN 2029-7025 (online)

2020 Volume 9 January

http://doi.org/10.9770/jssi.2020.9.J(3)

The q-square value of the JP (0.539) and OC (0.662) are indicating that the predictive ability of the current model is high.

Table 7. Q-square

\begin{tabular}{|l|l|l|l|}
\hline & SSO & SSE & $\mathbf{Q}^{\mathbf{2}}$ (=1-SSE/SSO) \\
\hline $\mathbf{C E}$ & $2,170.000$ & $2,170.000$ & \\
\hline $\mathbf{J P}$ & $2,170.000$ & 999.491 & 0.539 \\
\hline $\mathbf{K M}$ & $2,387.000$ & $2,387.000$ & \\
\hline $\mathbf{O C}$ & 868.000 & 293.716 & 0.662 \\
\hline
\end{tabular}

\section{Conclusion}

The concept of knowledge management is not new. This has been analyzed from different perspectives and in different ways. Knowledge is built by humans throughout their lives. History books are used by individuals for gaining knowledge regarding past. This helps in avoiding the previously done mistakes and make inventions. The knowledge is managed by individuals unconsciously. It can be used in the best manner. Knowledge management is not based on a software system even in the technologically supportive working environment. Knowledge management can be easily done through use of software. However, expertise cannot be developed by it. The data is collected with the aid of a questionnaire, that is adopted from the prior studies. The study has used the structural equation modeling for the analysis of the data. At earlier stages it is suggested to apply PLS modelling that is at theoretical development stage which let the researcher to confirm and examine the experimental models. determining the direct relationship between compete entrepreneurship, knowledge management, organizational commitment, and the job performance are significant at p-value less than 0.05 . The findings of the study highlighted that the compete entrepreneurship, knowledge management, are significant determinants of the organizational commitment. Meanwhile, the study has confirmed that the organizational commitment, mediate in the relationship between corporate entrepreneurship, and job performance, and between the knowledge management and the job performance. It was also found that some unique challenges are possessed by sharing of knowledge in IT sector. Creativity is engaged along with reward system to promote sharing of knowledge. Moreover, the knowledge distribution process becomes complicated because of naturally bureaucratic and hierarchical organizational structure in IT sector. Evidence was found by researchers that organizational commitment and employee involvement are the cultural variables, which create influence on practices of human resource management. However, performance and productivity are influenced as well.

\section{References}

Ahmed, N. O. A. (2016). Human resource management practices and corporate entrepreneurship. The mediating role of organizational commitment. International Business Management, 10(9), 1632-1638 http://dx.doi.org/10.36478/ibm.2016.1632.1638

Al-Kahtani, N.S. (2018). Perception of private telecom employees towards unfair HRM practices: an empirical investigation, Entrepreneurship and Sustainability Issues, 5(4), 957-966. http://doi.org/10.9770/jesi.2018.5.4(18)

Alkhuraiji, A., Liu, S., Oderanti, F. O., \& Megicks, P. (2016). New structured knowledge network for strategic decision-making in IT innovative and implementable projects. Journal of Business Research, 69(5), 1534-1538. https://doi.org/10.1016/j.jbusres.2015.10.012 


\section{JOURNAL OF SECURITY AND SUSTAINABILITY ISSUES ISSN 2029-7017/ISSN 2029-7025 (online) 2020 Volume 9 January http://doi.org/10.9770/jssi.2020.9.J(3)}

An, W., Zhao, X., Cao, Z., Zhang, J., \& Liu, H. (2018). How bricolage drives corporate entrepreneurship: The roles of opportunity identification and learning orientation. Journal of Product Innovation Management, 35(1), 49-65. https://doi.org/10.1111/jpim.12377

Anesukanjanakul, J., Banpot, K., \& Jermsittiparsert, K. (2019). Factors That Influence Job Performance of Agricultural Workers. International Journal of Innovation, Creativity and Change, 7(2), 71-86.

Argyris, C. (2017). Integrating the Individual and the Organization: Routledge. https://doi.org/10.4324/9780203788417

Becton, J. B., Carr, J. C., Mossholder, K. W., \& Walker, H. J. (2017). Differential effects of task performance, organizational citizenship behavior, and job complexity on voluntary turnover. Journal of Business and Psychology, 32(4), 495-508. https://doi.org/10.1007/s10869$\underline{016-9461-\mathrm{x}}$

Bedoya, M. A., Alzate, B. A., \& Giraldo, L. M. (2018). Corporate entrepreneurship and entrepreneurial orientation: The impact on managing capabilities for innovation. Paper presented at the 2018 Portland International Conference on Management of Engineering and Technology (PICMET). https://doi.org/10.23919/PICMET.2018.8481851

Bernardi, A. (2019). The capability approach and organizational climate as tools to study occupational health and safety. Insights into Regional Development, 1(2), 155-169. https://doi.org/10.9770/ird.2019.1.2(6)

Biscotti, A. M., D’Amico, E., \& Monge, F. (2018). Do environmental management systems affect the knowledge management process? The impact on the learning evolution and the relevance of organisational context. Journal of Knowledge Management, 22(3), 603-620. https://doi.org/10.1108/JKM-08-2017-0344

Bogdanović, M., Vetráková, M., Filip, S. (2018). Dark triad characteristics between economics \& business students in Croatia \& Slovakia: what can be expected from the future employees? Entrepreneurship and Sustainability Issues, 5(4), 967-991. http://doi.org/10.9770/jesi.2018.5.4(19)

Borisov, A., Narozhnaia, D., Tarando, E., Vorontsov, A., Pruel, N., Nikiforova, O. (2018). Destructive motivation of personnel: a case study of Russian commertcial companies. Entrepreneurship and Sustainability Issues, 6(1), 253-267. http://doi.org/10.9770/jesi.2018.6.1(16)

Brahma, S., \& Mishra, S. (2015). Understanding Researchable Issues in Knowledge Management: A Literature Review. IUP Journal of Knowledge Management, 13(4).

Butt, M. A., Nawaz, F., Hussain, S., Sousa, M. J., Wang, M., Sumbal, M. S., \& Shujahat, M. (2019). Individual knowledge management engagement, knowledge-worker productivity, and innovation performance in knowledge-based organizations: the implications for knowledge processes and knowledge-based systems. Computational and Mathematical Organization Theory, 25(3), 336-356. https://doi.org/10.1007/s10588-018-9270-z

Chen, Y., Wang, Y., Nevo, S., Benitez-Amado, J., \& Kou, G. (2015). IT capabilities and product innovation performance: The roles of corporate entrepreneurship and competitive intensity. Information \& Management, 52(6), 643-657. https://doi.org/10.1016/j.im.2015.05.003 Drucker, P. F. (1992). of Organizations. Harvard business review, 20, 281-293.

Ericsson, K. A. (2015). Acquisition and maintenance of medical expertise: a perspective from the expert-performance approach with deliberate practice. Academic Medicine, 90(11), 1471-1486. https://doi.org/10.1097/ACM.0000000000000939

Ferraris, A., Santoro, G., \& Dezi, L. (2017). How MNC's subsidiaries may improve their innovative performance? The role of external sources and knowledge management capabilities. Journal of Knowledge Management, 21(3), 540-552. https://doi.org/10.1108/JKM-09$\underline{2016-0411}$

Fornell, C., \& Larcker, D. F. (1981). Structural equation models with unobservable variables and measurement error: Algebra and statistics: SAGE Publications Sage CA: Los Angeles, CA.

Ha, S.-T., Lo, M.-C., \& Wang, Y.-C. (2016). Relationship between knowledge management and organizational performance: a test on SMEs in Malaysia. Procedia-Social and Behavioral Sciences, 224, 184-189. https://doi.org/10.1016/j.sbspro.2016.05.438

Hair, J. F., Ringle, C. M., \& Sarstedt, M. (2011). PLS-SEM: Indeed a silver bullet. Journal of Marketing theory and Practice, 19(2), 139-152. https://doi.org/10.2753/MTP1069-6679190202 


\section{JOURNAL OF SECURITY AND SUSTAINABILITY ISSUES ISSN 2029-7017/ISSN 2029-7025 (online) 2020 Volume 9 January http://doi.org/10.9770/jssi.2020.9.J(3)}

Hair Jr, J.F., Sarstedt, M., Hopkins 1., \& Kuppelwieser, V. G. (2014). Partial least squares structural equation modeling (PLS-SEM) An emerging tool in business research. European Business Review, 26(2), 106-121. https://doi.org/10.1108/EBR-10-2013-0128

Hoque, A., Gwadabe, U. M., \& Rahman, M. A. (2017). Corporate entrepreneurship upshot on innovation performance: The mediation of employee engagement. Journal of Humanities, Language, Culture and Business, 1(6), 54-67.

Jain, A. K., \& Moreno, A. (2015). Organizational learning, knowledge management practices and firm's performance: an empirical study of a heavy engineering firm in India. The Learning Organization, 22(1), 14-39. https://doi.org/10.1108/TLO-05-2013-0024

Jermsittiparsert, K., Suan, C., \& Kaliappen, N. (2019). The Mediating Role of Organizational Commitment and the Moderating Role of Perceived Organizational Support in the Relationship between Job Satisfaction and Job Performance of Educationists in Public Sector Institutes of Thailand. International Journal of Innovation, Creativity and Change, 6(10), 150-171.

Judge, T. A., \& Zapata, C. P. (2015). The person-situation debate revisited: Effect of situation strength and trait activation on the validity of the Big Five personality traits in predicting job performance. Academy of Management Journal, 58(4), 1149-1179. https://doi.org/10.5465/amj.2010.0837

Kamruddin, S., \& Akram, M. W. (2016). Knowledge Management Practices in Information Technology Sector in India: A Study. Journal Impact Factor, 7(2), 652-662.

Koriat, N., \& Gelbard, R. (2018). Knowledge Sharing Motivation among External and Internal IT Workers. Journal of Information \& Knowledge Management, 17(03), 1850026. https://doi.org/10.1142/S0219649218500260

Kwahk, K.-Y., \& Park, D.-H. (2016). The effects of network sharing on knowledge-sharing activities and job performance in enterprise social media environments. Computers in Human Behavior, 55, 826-839. https://doi.org/10.1016/j.chb.2015.09.044

Kwofie, T. E., Botchway, E. A., \& Amos-Abanyie, S. (2018). Examining the Performance Level of Project Management Competencies of Architects in Ghana Using Gap Analysis Approach. https://doi.org/10.21315/jcdc2018.23.1.8

Lohmann, J., Wilhelm, D., Kambala, C., Brenner, S., Muula, A. S., \& De Allegri, M. (2017). 'The money can be a motivator, to me a little, but mostly PBF just helps me to do better in my job.' An exploration of the motivational mechanisms of performance-based financing for health workers in Malawi. Health policy and planning, 33(2), 183-191. https://doi.org/10.1093/heapol/czx156

Maier, R., \& Hadrich, T. (2011). Knowledge management systems Encyclopedia of Knowledge Management, Second Edition (pp. 779-790): IGI Global.

Malarvizhi, C. A., Mamun, A. A., Prabadevi, M., Nawi, N. B. C., Rasti, A., \& Permarupan, P. Y. (2016). Knowledge Infrastructure, Process, and the Effectiveness of Manufacturing SMEs in Selangor, Malaysia. Advanced Science Letters, 22(5-6), 1730-1732. https://doi.org/10.1166/asl.2016.6750

Mao, H., Liu, S., Zhang, J., \& Deng, Z. (2016). Information technology resource, knowledge management capability, and competitive advantage: The moderating role of resource commitment. International Journal of Information Management, 36(6), 1062-1074. https://doi.org/10.1016/j.ijinfomgt.2016.07.001

Masa'deh, R. e., Shannak, R., Maqableh, M., \& Tarhini, A. (2017). The impact of knowledge management on job performance in higher education: The case of the University of Jordan. Journal of Enterprise Information Management, 30(2), $244-262$. https://doi.org/10.1108/JEIM-09-2015-0087

Massaro, M., Dumay, J., \& Garlatti, A. (2015). Public sector knowledge management: a structured literature review. Journal of Knowledge Management, 19(3), 530-558. https://doi.org/10.1108/JKM-11-2014-0466

Noor, M. M., Kamardin, H., \& Ahmi, A. (2016). The Relationship between Board Diversity of Information and Communication Technology Expertise and Information and Communication Technology Investment: A Review of Literature. International Journal of Economics and Financial Issues, 6(7S), 202-214. 


\section{JOURNAL OF SECURITY AND SUSTAINABILITY ISSUES ISSN 2029-7017/ISSN 2029-7025 (online) 2020 Volume 9 January http://doi.org/10.9770/jssi.2020.9.J(3)}

Popadic, M., Pucko, D., \& Cerne, M. (2016). Exploratory innovation, exploitative innovation and innovation performance: the moderating role of alliance partner diversity/raziskovalne inovacije, uporabne inovacije in ucinkovitost inovacij: vloga moderiranja povezanih raznolikih partnerjev. Economic and Business Review for Central and South-Eastern Europe, 18(3), 293. https://doi.org/10.1080/1331677X.2016.1211951

Preacher, K. J., Zyphur, M. J., \& Zhang, Z. (2010). A general multilevel SEM framework for assessing multilevel mediation. Psychological Methods, 15(3), 209. https://doi.org/10.1037/a0020141

Rimer, E. (1993). Organization theory and Frederick Taylor: JSTOR. https://doi.org/10.2307/3110137

Singh, A. (2018). Detailed Literature Review: Antecedents Affecting the Flight Risk or Turnover Intention of Professionals. Ushus-Journal of Business Management, 17(2), 41-68. https://doi.org/10.12725/ujbm.43.4

Soto-Acosta, P., Popa, S., \& Palacios-Marqués, D. (2016). E-business, organizational innovation and firm performance in manufacturing SMEs: an empirical study in Spain. Technological and Economic Development of Economy, 22(6), 885-904. https://doi.org/10.3846/20294913.2015.1074126

Story, V. M., Boso, N., \& Cadogan, J. W. (2015). The form of relationship between firm-level product innovativeness and new product performance in developed and emerging markets. Journal of Product Innovation Management, 32(1), 45-64. https://doi.org/10.1111/jpim.12180

Umrani, W. A., Kura, K. M., \& Ahmed, U. (2018). Corporate entrepreneurship and business performance: The moderating role of organizational culture in selected banks in Pakistan. PSU Research Review, 2(1), 59-80. https://doi.org/10.1108/PRR-12-2016-0011

Unterhitzenberger, C., \& Bryde, D. J. (2019). Organizational justice, project performance, and the mediating effects of key success factors. Project Management Journal, 50(1), 57-70. https://doi.org/10.1177\%2F8756972818808984

Zainal, H., Parinsi, K., Hasan, M., Said, F., \& Akib, H. (2018). The influence of strategic assets and market orientation to the performance of family business in Makassar City, Indonesia. Academy of Strategic Management Journal, 17(6).

Chutikarn SRIVIBOON is a Lecturer of Doctor of Philosophy Program in Development Administration, Suan Sunandha Rajabhat University, Thailand. Her research areas are Leadership, Human Resources Management, and Innovation Management.

ORCID ID: orcid.org/0000-0002-9667-3730

This work is licensed under the Creative Commons Attribution International License (CC BY). http://creativecommons.org/licenses/by/4.0/ 